
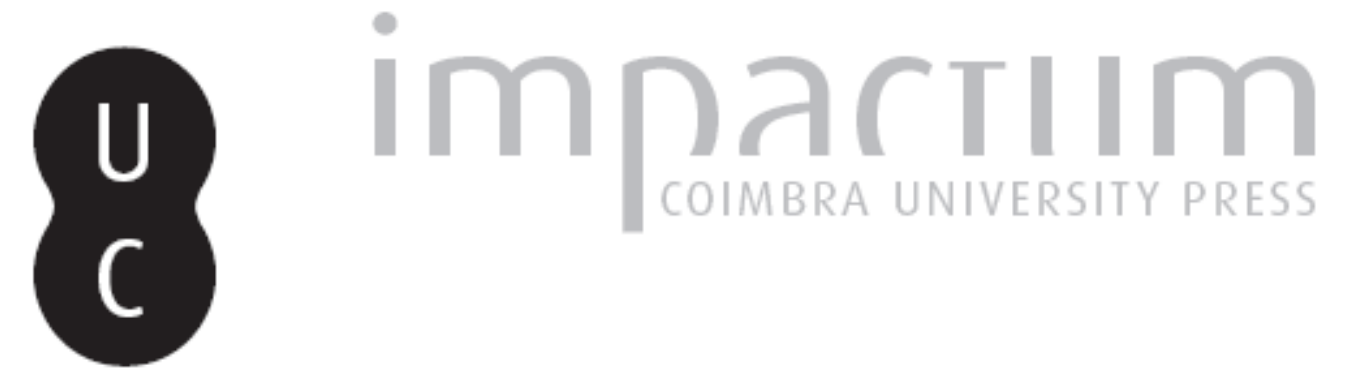

\title{
A antiga fábrica da Companhia de Moagens Harmonia: entre o poder da arquitectura e o poder do arquitecto
}

\author{
Autor(es): Rapagão, João Paulo
}

Publicado por: Editorial do Departamento de Arquitetcura

URL persistente:

URI:http://hdl.handle.net/10316.2/37409

DOI:

DOI:http://dx.doi.org/10.14195/0874-6168_1_4

Accessed : $\quad$ 26-Apr-2023 10:58:21

A navegação consulta e descarregamento dos títulos inseridos nas Bibliotecas Digitais UC Digitalis, UC Pombalina e UC Impactum, pressupõem a aceitação plena e sem reservas dos Termos e Condições de Uso destas Bibliotecas Digitais, disponíveis em https://digitalis.uc.pt/pt-pt/termos.

Conforme exposto nos referidos Termos e Condições de Uso, o descarregamento de títulos de acesso restrito requer uma licença válida de autorização devendo o utilizador aceder ao(s) documento(s) a partir de um endereço de IP da instituição detentora da supramencionada licença.

Ao utilizador é apenas permitido o descarregamento para uso pessoal, pelo que o emprego do(s) título(s) descarregado(s) para outro fim, designadamente comercial, carece de autorização do respetivo autor ou editor da obra.

Na medida em que todas as obras da UC Digitalis se encontram protegidas pelo Código do Direito de Autor e Direitos Conexos e demais legislação aplicável, toda a cópia, parcial ou total, deste documento, nos casos em que é legalmente admitida, deverá conter ou fazer-se acompanhar por este aviso.

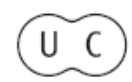




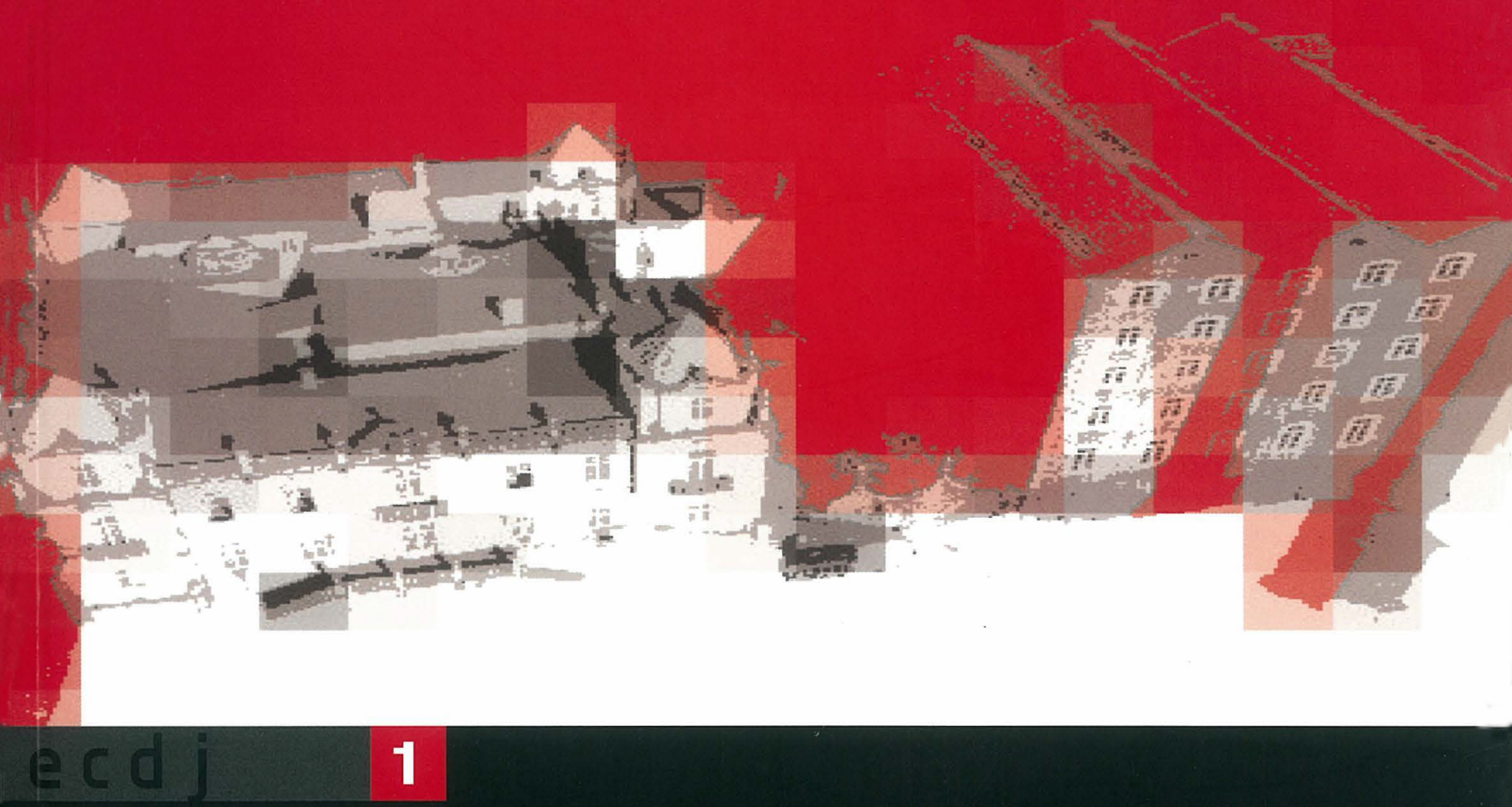

fctuc / departamento de arquitectura

\section{a polémica do Freixo Fernando Távora} alexandre alves costa | antónio olaio joão paulo rapagão | jorge figueira josé antónio bandeirinha

(2) 


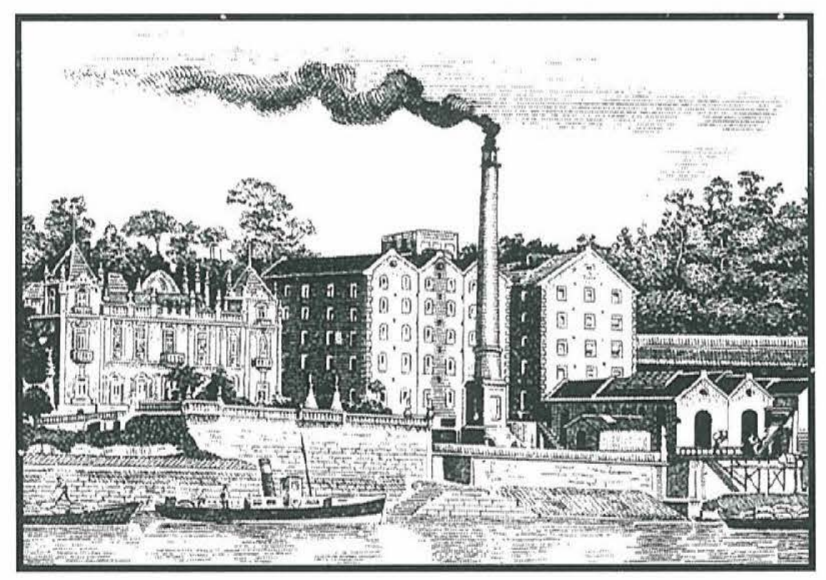




\title{
[a antiga fábrica da companhia de moagens harmonia entre o poder da arquitectura e o poder do arquitecto]
}

\author{
João Paulo RAPAGÃo
}

1 | A antiga fábrica da Companhia de Moagens Harmonia integra um conjunto de elementos não construídos e construídos dos quais fazem parte o Palácio do Freixo e a nova fábrica implantada a Norte da paisagem. Este quadro, envolvido e unido pela topografia da encosta voltada para o Rio Douro é descritivo e representa um documento revelador do desenvolvimento do espaço urbano da cidade do Porto nos últimos duzentos anos, nomeadamente, pelo seu testemunho no aparecimento e crescimento da idade industrial, importante para a sua compreensão e interpretação.

Os elementos existentes organizam uma sucessão no espaço e no tempo com uma leitura fácil e útil. Assim, o lugar recebeu o palácio que gerou a antiga fábrica que originou, mais tarde, a nova instalação industrial. O aparecimento progressivo dos elementos integrados na ecd j $+\bar{c} \cdot 35$ paisagem demonstra, ainda, o desejo de relacionamento dos espaços anteriores e ulteriores ao momento industrial com o rio, fonte de observação e de sustentação da função produtiva. O campo paisagístico descreve e entende, assim, um percurso espacial e temporal revelador da sua história. 
A unidade topográfica gerou uma unidade arquitectónica que encontra o seu equilíbrio na apropriação da topografia e na concepção da quinta barroca. A partir da matriz instalada, capaz de reforçar as linhas naturais existentes, esta matriz concebe e recebe uma fábrica que é um elemento de continuidade do Palácio do Freixo. Esta apropriação representa, paralelamente, utilizando a arquitectura como expressão, a materialização orgulhosa da afirmação e representação industrial.

A antiga fábrica adopta e reforça os eixos de composição e de organização do Palácio do Freixo, originando um conjunto caracterizado pela vontade de conceber e construir uma unidade morfológica, lida quando a fábrica aparece associada ao Palácio do Freixo na definição do Alçado Sul voltado para o Rio Douro. Hoje, perante uma envolvente em transformação que apresenta uma imagem desqualificada, a fábrica representa um elemento auxiliar na restituição da leitura do Palácio do Freixo que nıo consegue, individualmente, a afirmação da escala e do valor próprios.

A sua arquitectura, iniciada no século XIX e transformada no século $X X$, surge, hoje, com a responsabilidade e a qualidade que resultam da sua capacidade de apropriação dos valores barrocos e de transformação dos valores industriais, entre o palácio e a nova fábrica da Companhia de Moagens Harmonia. Importa, por isso, aqui, perante este quadro, deixar ler e interpretar a narração da história, parte integrante da sua identidade. Importa, ainda, explicitar as fases de desenvolvimento dos diversos elementos que devem, assim, ser usados e trabalhados como matéria prima do projecto e da obra.

A sua concepção e a sua construção acusam o respeito pela estrutura existente. As linhas que regulam e organizam o espaço do século XVIII são adoptadas e prolongadas, gerando os espaços industriais, nomeadamente, a sua malha estrutural, e produzindo os terraços que modelam a topografia desfavorável à produção de um espaço barroco. Este desejo é visivel, ainda, na construção e materialização dos seus paramentos verticais exteriores que adoptam o granito. Entre a arquitectura do ferro e a arquitectura da pedra, a nível formal e a nível material, a antiga fábrica representa um dos valores mais 
significativos para o estudo do lugar e da história da cidade pela descrição das ideias e dos actos.

A antiga fábrica da Companhia de Moagens Harmonia representa, assim, entre a afirmação da identidade industrial e a colonização da intensidade barroca, um símbolo do seu tempo. Este desejo revela, hoje, um exemplar da arquitectura industrial com características que denunciam a sua vocação e afirmam a sua contribuição para uma interpretação da história da indústria no Porto.

A sua tipologia é afirmada na paisagem pela marcação de uma verticalidade que pontua com vigor o lugar. A imposição da verticalidade revela um desejo de construção da paisagem, procurando o equilíbrio das linhas que informam o lugar, dominado pela implantação dos terraços horizontais. A presença da chaminé, para além de representar uma marca industrial, afirma e identifica a sua tipologia, reforçada pela sombra produzida pelo perfil recortado dos volumes Nascente e Poente que confirma a vontade de se constituir, no seu tempo, um reflexo de modernidade e contemporaneidade. O seu interior é moderno, constituído por espaços facilmente colonizáveis, mutáveis, flexíveis e adaptáveis a utilizações diversas.

A tipologia fabril produz um edifício que estrutura espaços caracterizados por uma ordem abstracta. A modulação e racionalização da sua estrutura constituem a modernidade e a validade da solução que permitiu e permite a sua adaptação constante à evolução técnica. Esta composição, regulada pelo palácio mas transformada pela abstracção da sua utilização é, no entanto, trabalhada e enriquecida com preocupações de enquadramento e de relacionamento com o Palácio do Freixo que originam o aparecimento de apontamentos materiais e formais pontuais que transportam valores respeitados e interpretados para os alçados da antiga fábrica.

A normalização e a abstracção da estrutura de ferro que se agarra à estrutura de pedra interpreta a fidelidade ao passado. A solução, ditada por condicionantes funcionais, acaba por construir e constituir 
um objecto arquitectónico recheado de observações e de interpretações que motivam a imaginação. As suas naves, marcadas no exterior, confirmam a tipologia e definem uma imagem identificada e facilmente apreensível e relacionada com o seu uso.

O Alçado Norte, voltado para a Estrada Nacional 108, representa a síntese do conjunto. Mais urbano, traduz a dualidade e a versatilidade de um imóvel que procura, a Sul, uma modulação e uma articulação motivada pela topografia e, a Norte, uma limitação ditada pela relação com a cidade e, principalmente, com a estrada que o serve. O Alçado Sul confirma a relação formal e funcional com rio que o serviu.

A hierarquia das partes que constituem o conjunto, com os edifícios principais e auxiliares das estruturas de concepção da fábrica e de organização do espaço representam, hoje, uma vez que a desafectação da antiga fábrica é recente, um documento legível e utilizável, com o critério de uma autenticidade fácil de revelar e de interpretar através de uma intervenção rigorosa.

2 | A relação entre as duas arquitecturas está fixada há cem anos. A identidade do espaço barroco representa uma síntese que é capaz de aglutinar e articular a diversidade das formas que se encontram na paisagem voltada para o Rio Douro. É, por isso, capaz de subtrair e adicionar outros elementos construídos e não construídos.

As actuações efectuadas nos últimos cem anos provam que a organização e composição barrocas possuem a enorme capacidade de absorver e gerir os novos elementos, integrando, hierarquizando, relacionando e materializando um espaço que revela a sua universalidade.

A legitimidade da antiga fábrica fica avaliada e demonstrada, ainda, na data em que foi concebida, pela sua localização e implantação. Há cem anos, a opção de localizar e implantar a fábrica perto da porta de casa revela a afirmação do significado da marca industrial. Este acto, localizado no tempo e no espaço, deve, por isso, ser observado, estudado, preservado e interpretado. 
3 | "Mas, porque o espaço é continuo e porque o tempo é uma das suas dimensões, o espaço é, igualmente, irreversível, isto é, dada a marcha constante do tempo e de tudo o que tal marcha acarreta e significa, um espaço organizado nunca pode vir a ser o que já foi, donde ainda a afirmação de que o espaço está em permanente devir. Quando, por exemplo, ao restaurar um monumento com critério "cientifico" (ou pseudo-científico) passa pela cabeça de alguém dar a tal monumento o aspecto que ele teve em época mais ou menos passada, cai-se na utopia de supor que aquilo que já foi pode de novo vir a ser, esquecendo-se que a irreversibilidade do espaço não permite aceitar tal hipótese. Diga-se aliás, e de passagem, que os antigos tinham uma noção clara deste facto pois que os seus "restauros" - a que davam certamente outro nome - eram feitos com critério mais realista e um sentido mais dinâmico do espaço organizado"(1).

4 | O quadro descrito remete para uma reflexão que acaba por revelar e validar a sua lógica espacial e temporal. Os elementos não construídos e construídos narram uma história que não pode esquecer ou apagar as partes porque pode desvirtuar o todo. A sua eliminação, adulteração ou deslocação anulam a conservação e a interpretação de um valor que documenta e testemunha a ocupação do espaço urbano nos últimos duzentos anos.

Entre o poder da arquitectura e o poder do arquitecto, fica, aqui, o respeito pelo valor patrimonial e, principalmente, cultural da cidade, contada na encosta da Quinta do Freixo e fixada no leito do Rio Douro. 